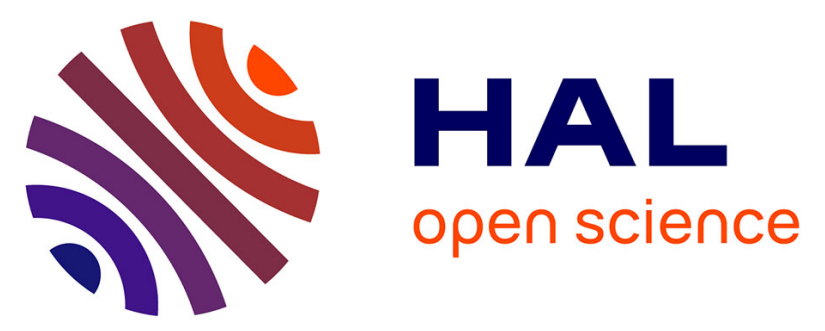

\title{
Progress of the COST Action TU1402 on the Quantification of the Value of Structural Health Monitoring
}

Sebastian Thöns, Maria Pina Limongelli, Ana Mandic Ivankovic, Michael Faber, Dimitri Val, Marios Chryssanthopoulos, Geert Lombaert, Michael Döhler, Daniel Straub, Eleni Chatzi, et al.

\section{To cite this version:}

Sebastian Thöns, Maria Pina Limongelli, Ana Mandic Ivankovic, Michael Faber, Dimitri Val, et al.. Progress of the COST Action TU1402 on the Quantification of the Value of Structural Health Monitoring. IWSHM - 11th International Workshop on Structural Health Monitoring, Sep 2017, Stanford, United States. 10.12783/shm2017/14002 . hal-01589527

\section{HAL Id: hal-01589527 https://hal.inria.fr/hal-01589527}

Submitted on 18 Sep 2017

HAL is a multi-disciplinary open access archive for the deposit and dissemination of scientific research documents, whether they are published or not. The documents may come from teaching and research institutions in France or abroad, or from public or private research centers.
L'archive ouverte pluridisciplinaire HAL, est destinée au dépôt et à la diffusion de documents scientifiques de niveau recherche, publiés ou non, émanant des établissements d'enseignement et de recherche français ou étrangers, des laboratoires publics ou privés. 


\section{COVER SHEET}

Title: Progress of the COST Action TU1402 on the Quantification of the Value of Structural Health Monitoring for Proceedings of the $11^{\text {th }}$ International Workshop on Structural Health Monitoring 2017

Authors: Sebastian Thöns, Maria Pina Limongelli, Ana Mandic Ivankovic, Michael H. Faber, Dimitri Val, Marios Chryssanthoplous, Geert Lombaert, Michael Döhler, Daniel Straub, Eleni Chatzi, Jochen Köhler, Helmut Wenzel, John D. Sørensen 


\title{
(FIRST PAGE OF ARTICLE)
}

\begin{abstract}
This paper summarizes the development of Value of Structural Health Monitoring (SHM) Information analyses and introduces the development, objectives and approaches of the COST Action TU1402 on this topic. SHM research and engineering has been focused on the extraction of loading, degradation and structural features for damage detection and condition assessment, system identification and model updating. However, there is an actual challenge to establish a better understanding of the value of SHM before its implementation in terms of its utility in conjunction with practically applicable methods for its quantification. This challenge can be met with Value of SHM Information analyses facilitating that the SHM contribution to substantial benefits for life safety, economy and beyond can be may be quantified, demonstrated and utilized. However, Value of SHM Information analyses involve complex models encompassing the infrastructure and the SHM systems, their functionality and thus require the interaction of several research disciplines. For progressing on these points, a scientific networking and dissemination project namely the COST Action TU1402 has been initiated.
\end{abstract}

Sebastian Thöns, ERDA Group, Department of Civil Engineering, Technical University of Denmark, Anker Engelunds Vej 1, 2800 Kgs. Lyngby, Denmark

Maria Pina Limongelli. Department Architecture, Built Environment and Construction Engineering. Politecnico di Milano. Piazza Leonardo da Vinci,32. 20133 Milano. Italy

Ana Mandić Ivanković, Faculty of Civil Engineering, University of Zagreb, Kačićeva 26, 10000 Zagreb, Croatia

Michael H. Faber, Department of Civil Engineering, Aalborg University, Denmark

Dimitri Val, Institute for Infrastructure \& Environment, Heriot-Watt University, Edinburgh, UK

Marios Chryssanthopoulos, University of Surrey, UK

Geert Lombaert, Department of Civil Engineering, KU Leuven, Belgium

Michael Döhler, Inria, I4S, Campus de Beaulieu, Rennes, France, and IFSTTAR, COSYS, SII, Bouguenais, France

Daniel Straub, TUM Department of Civil, Geo and Environmental Engineering, Technical University of Munich, Germany

Eleni Chatzi, Department of Civil, Environmental, and Geomatic Engineering, ETH Zurich

Jochen Kohler, Department of Structural Engineering Faculty of Engineering, Richard Birkelands vei 1a, 7491 Trondheim, Norway.

Helmut Wenzel, WENZEL Consulting Engineers $\mathrm{GmbH}$, University of Natural Resources and Life Sciences, Vienna, Austria

John D. Sørensen, Department of Civil Engineering, Aalborg University, Denmark 


\section{INTRODUCTION}

The ultimate goal of Structural Health Monitoring is perceived as damage prognosis associated with "tremendous economic and life-safety benefits that these technologies can offer", see [23], [7] and [9]. Despite this knowledge, approaches for explicitly quantifying and predicting the structural system safety and economic benefits triggered by SHM have only very recently been developed.

The field of Structural Health Monitoring (SHM) developed in the second half of the last century when engineers were challenged by complex construction projects and structural measurement technologies emerged. This evolution was accelerated with the use of electronic data processing, storage technologies and software development for data analysis algorithms. Hitherto, SHM has been approached with mainly the objectives to develop approaches for damage detection and assessment, for model identification and for the extraction of loading and degradation and structural features, see e.g. [23], [34] and [2]. Lately, one of the foci has been on uncertainty treatment and probabilistic representation and e.g. damage detection has been associated to statistical testing approaches, as e.g. described in [1], [4], [3], [12] and [26]. SHM is widely applied to various types of infrastructures, such as offshore structures, bridges, dams, power plants, towers and tunnels [33], [32].

A step towards explicitly quantifying and predicting the structural system safety in conjunction with SHM has been performed by Todd (e.g. [10], [11]). Here, an approach called Bayesian experimental design (BED) is formulated which is based on an objective loss function including an expected cost calculation for a structure equipped with an SHM system. The approach is applied for sensor placement optimization and damage detection system performance optimization.

The consistent and comprehensive quantification and prognosis of the structural reliability and the expected benefits and costs triggered by SHM is facilitated with the Bayesian decision analysis and the concept of the Value of Information (VoI). Early approaches for the quantification of the value of SHM include the works by [19] and [28] extended in [30] and [6]. Herein, the principal utilization of the Value of Information theory for the field of SHM is proposed, formulated and exemplarily demonstrated. Since then, the topic has attracted more interest and researchers worked on theoretical advancements and implementation on a variety of cases and/or the initiation of projects. Straub [24] presents a modelling and computation framework of VoI for SHM based on structural reliability methods. It therein mentioned that the challenges for the application of VoI regard the probabilistic modelling of monitoring data and the monitored process, the assessment and modelling of actions triggered by the monitoring information as well as the computational efforts. Zonta et. al. [35] present a methodology for economic evaluation of the impact of monitoring on bridge management using monitoring and VoI theory. Monitoring is here defined as any information about the structure obtained by e.g. visual inspection, integrity consultants and archive research. The methodology is partly applied to the simplified case of the Streicker Bridge.

The analysis of these approaches and studies for the quantification of the Value of SHM Information substantiated the expectation of significant expected benefits both in regard to the safety and to economy. However, in order to fully exploit these potentials scientifically, economically and thus societal, it was found that the development, 
application, dissemination and standardization of (1) a systematic and comprehensive approach and framework, (2) of the required methods and tools and (3) of a variety of applications is required. To this aim it essential that the two basic scientific and engineering communities researching on SHM and on structural performance need to work integrally. Due to these observations, it was decided to initiate a scientific networking and research project in the frame of European Intergovernmental Framework for Cooperation in Science and Technology (COST): The COST Action TU1402 on Quantifying the Value of Structural Health Monitoring.

\section{TU1402 SCIENTIFIC APPROACH AND PROGRESS}

The scientific approach for the quantification of the Value of SHM Information builds upon the Bayesian decision theory and specifically on the pre-posterior decision and Value of Information analysis [21]. The pre-posterior decision analysis facilitates a quantification and optimization of risks and expected benefits prior to acquirement of the SHM Information, i.e., before the implementation of the monitoring strategies. The scientific approach is directed towards the development of approaches, a framework, methods, tools, examples and case studies needed for research, development, application and standardization associated to the quantification of the Value of SHM Information.

Since its initiation in 2015, the progress of the COST Action TU1402 encompasses (1) the creation of a network across Europe with international links, (2) research and networking, (3) the dissemination of the research results and (4) impacts on science and economy.

The creation of a network includes roughly 130 participants in 27 European countries plus Australia as an International Partner Country (IPC) and establishing links to International External Advisors. The network incorporates researchers, SHM engineers, structural engineers, European and national associations and confederations, authorities and policy makers at regional and European levels, relevant standardization bodies and code writers, teachers, lecturers and students of structural design and engineering schools. In order to motivate the generation of innovative and relevant research, an Innovation Committee and an Advisory Board have been created.

The research activities of the Action are organized within six Working Groups focusing on the Theoretical Framework (WG1), SHM Strategies and Structural Performance (WG2), Methods and Tools (WG3) and Case Study Portfolio (WG4), Standardization (WG5) and Dissemination (WG6). From 2015 to 2017 primarily Working Groups 1 to 3 have been primarily been active for preparation of the case studies (WG4) and standardization (WG5). The individual Working Group progress and plans are summarized in the consecutive sections.

The research results have been disseminated in 5 Special Sessions at international conferences (ICASP12 2015, MSSCE 2016, EWSHM 2016, ICOSSAR 2017 and IWSHM 2017), 9 dedicated Workshops across Europe amounting to about 40 peer reviewed publications and various workshop reports ([29], [15], [18] and [17]) documents and factsheets. Herewith scientific evidence for an improved economic efficiency in the safety, operation and maintenance and asset management of structures and infrastructure systems has been provided. 


\section{Working Group 1: Theoretical Framework}

Fundamental principles behind the quantification of the Value of SHM Information have been summarised and presented in a number of factsheets that have been published in the workshop reports [17] and [29]. These principles have set a basis for the theoretical framework developed by WG1. The work has been further extended in [5], which considers the infrastructure system utility modelling and decision analysis and describes how uncertain SHM information can propagate from the constituent to system level and vice versa influencing the aggregated expected utilities. This framework puts SHM into a wider perspective, i.e. (1) SHM may provide information about the system performance in terms of economy, human safety and the environment, (2) SHM encompasses information about any of the constituent and system performance states and (3) the Value of SHM Information is defined as a an expected utility gain which may account for an increase in the expected benefits of the system operation, reduction of the expected consequences and changes in the infrastructure system characteristics such as e.g. robustness, vulnerability and resilience. A variety of application areas has been identified and exemplary applications have been developed as documented e.g. in [14] [20], [27] and [31].

\section{Working Group 2: SHM Technologies and Structural Performance}

The purpose of SHM is the collection of information that is relevant for the system performance [8], [7]. For a given type of structure and structural performance, a selection of suitable SHM strategies can be made by qualitatively screening alternatives through knowledge and experience. Increasingly, there is a plethora of SHM technologies that can be deployed on civil engineering structures [2] and significant research is undertaken on diverse methods/tools for data interpretation.

Building on participants' experience, a framework has been proposed to structure the different concepts involved and to illustrate how alternatives may be considered systematically (Figure 1).

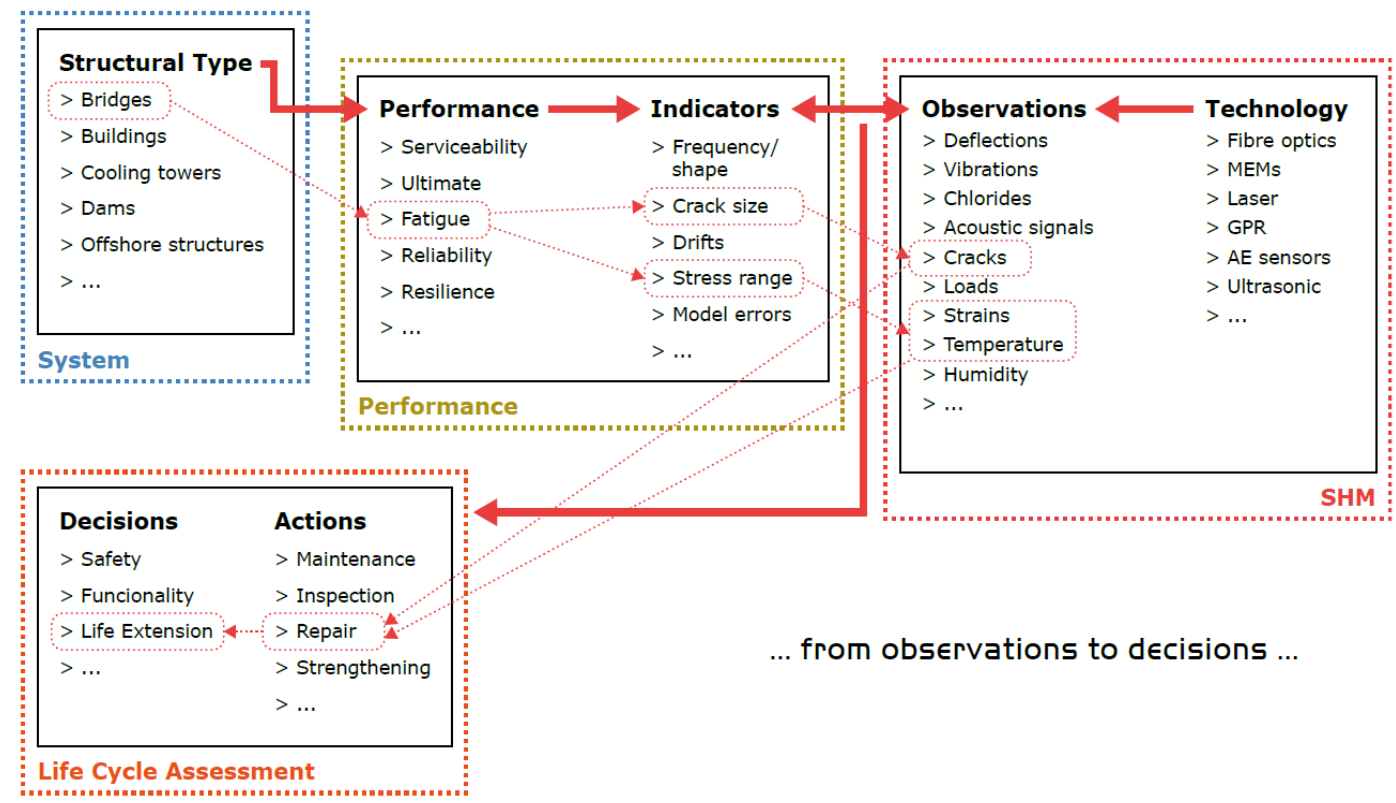

Figure 1: Framework for structuring and systematic the concepts when bringing SHM and system performance together. 
Furthermore, inherent measurement or model based uncertainties are relevant within all aspects of this framework, see e.g. [22]. A life-cycle approach accounting for these uncertainties is needed to assess expected benefits from SHM [16]. Current practice on uncertainty treatment has been collected from the participants for various applications.

\section{Working Group 3: Methods and Tools}

Value of Information models and associated probabilistic computations are often interlinked with considerable computational costs, due to the need for considering a large set of possible scenarios and decisions. While many methods and tools exist for the individual components of the VoI approach, these have seldom been put together for a complete VoI analysis. In a first step, efficient methods and tools will be developed to facilitate the application of the theoretical framework in practice. Such methods will take basis in modern methods of probabilistic systems analysis including Fully and Partially Observable Markov Decision processes, Bayesian Networks, Monte Carlo simulations schemes, stochastic meshing algorithms, First Order Reliability Methods, and combinations thereof. Considering the multiplicity of methods involved, successful incorporation into actual Operation and Maintenance schemes necessitates standardization of the models and methods undertaken and, ideally, development of corresponding software tools. To this end,

- A set of method-inspired tutorials will be made available by WG3 on the Action's website. A first such example will be on Bayesian Networks and Influence Diagrams for pre-posterior analysis (Figure 2).

- WG3 will further introduce guidelines for adoption of SHM technologies (instrumentation), established as an online interactive tool.

- Finally, a simulation benchmark will be established, to serve as a reference numerical experiment for members of the monitoring and reliability community at large.

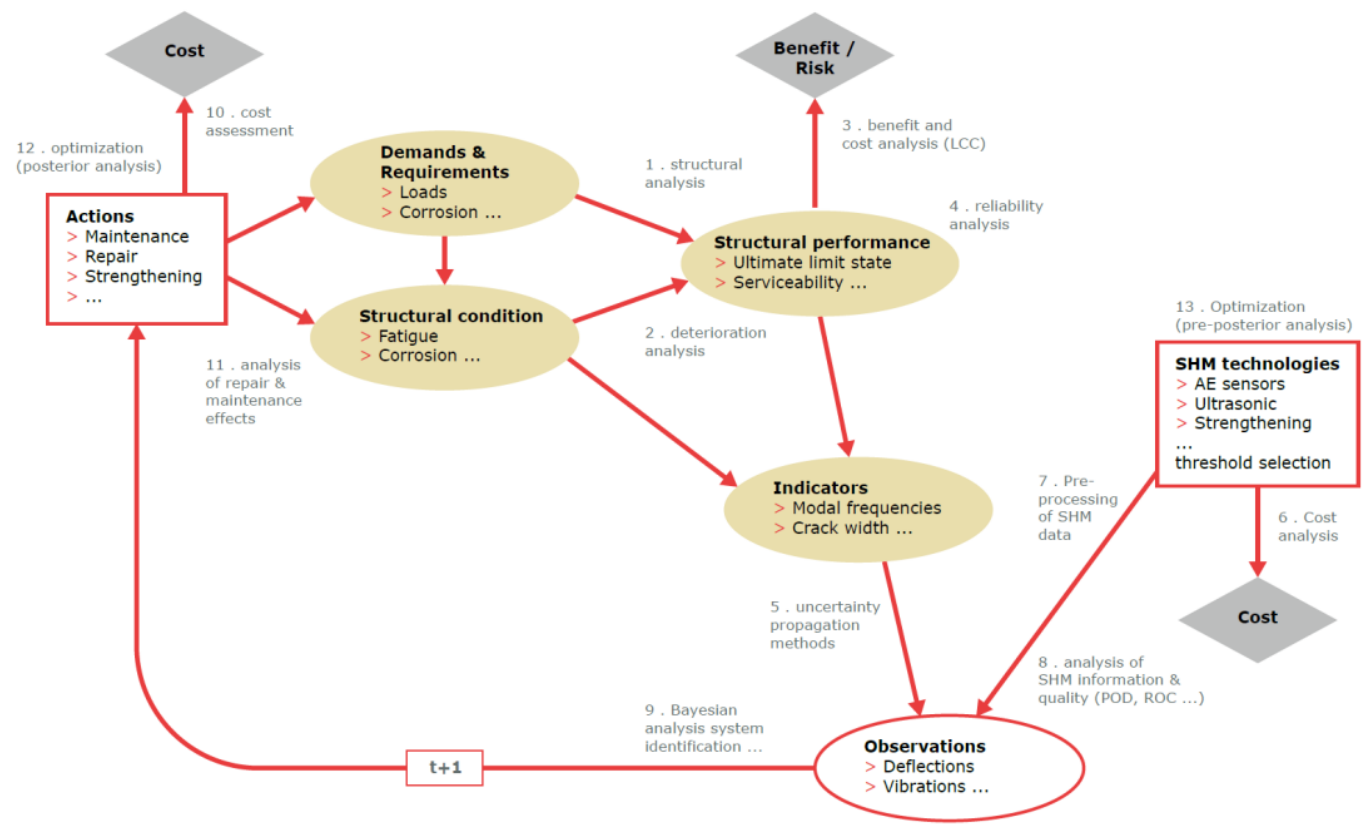

Figure 2: Influence diagram (ID) of the SHM analysis process. Green colors indicate parameters and models related to the structure, orange colors indicate those related to the SHM, red color indicates repair, maintenance and related actions. The yellow bubbles are the analysis methods and tools used in the different parts of the process. The box $[t+1]$ indicates that the edge is from one time step to the next, hence this ID represents a decision process in time [25]. 


\section{Working Group 4: Case Study Portfolio}

The benefit of Value of SHM Information assessment for the optimal maintenance strategy planning seems obvious. However, practical implementation is often hindered by the complexity of real systems and the corresponding decision situations. The objective of Working Group 4 is the identification of practical cases that demonstrate the practical feasibility in different sectors of civil engineering. The case studies highlight which combinations of SHM strategies are feasible under which conditions with respect to the type, precision and cost of the SHM information. In selecting them, the Action reviews carefully the problems faced by the various European infrastructure sectors, in order to focus attention in those areas where societal requirements and expectations are affected. Engagement with infrastructure owners/managers is actively pursued in this respect.

The dissemination and illustration of the potential of Value of SHM Information assessment along practical examples is the output of this Working Group.

\section{Working Group 5: Development of Guidelines}

In order to facilitate the fast implementation of the developed principles in Tasks 1 to 3 into practice, guideline documents are developed in this Working Group. The guidelines will focus on practical applications similar to the considered example cases studied in Working Group 4. Furthermore, a guideline serving as a scientific background document will be prepared and published as a chapter of the JCSS Probabilistic Model Code (PMC) [13]. Further, the guidelines will be linked to and standardization activities such as e.g. Eurocodes, ISO and IABSE.

\section{Working Group 6: Dissemination}

A major challenge of COST TU1402 is to disseminate the idea and the framework for assessing the value of SHM before its implementation amongst stakeholders not directly participating in the Action.

Dissemination is targeted to three groups of stakeholders: the research community (experts of the Action topic), enterprises (industry and SMEs), the general public (e.g. citizens, policy makers, generally not-experts of the Action topic).

Results of the Actions are disseminated, both in terms of networking (creation of the network and active collaborations on the Action topic) and in terms of scientific outcomes of the research project, tailoring the message and the language to the different targets. To this aim WG6 is actively engaged in dedicated activities aimed to continuously and promptly ensure the public diffusion of the progresses and results of the Action, and the dimension and composition of the network.

A printed brochure dedicated to the Action is distributed at scientific or industrially oriented conferences and at other events of the field.

Internet and social media are exploited through the creation of a website, a Linkedin group, a Facebook group, a Youtube video for the diffusion of the Action purposes and contents. One page of the website is dedicated to the activities of the Innovation Committee aimed to disseminate the possible industrial exploitation of the scientific results of the Action.

The Action website is constantly updated with video streams of keynote presentations from the Action workshops. The written material produced within the Action is available for public consultation on the website together with a glossary containing 
significant terms utilized in the fields of Value of Information and Structural Health Monitoring.

Special Sessions focused on VoI for SHM are organized in highly recognized and visible scientific and industrially oriented international conferences.

In order to disseminate the major scientific findings of the Action beyond dedicated publications in peer-reviewed journals, the publication of a Special Issue on VoI for SHM will be organized together with training courses directed to young researchers and practitioners.

\section{CONCLUDING REMARKS}

Structural Health Monitoring has been associated with ultimately providing "tremendous economic and life-safety benefits" already in 2004 [23]. However, explicit approaches for quantifying the SHM triggered economic and safety benefits started to develop in the early 10s (see e.g. [10], [19], [28], [30], [6] and [24]). SHM triggered economic and safety benefits are quantified building upon the Bayesian decision theory and specifically on the pre-posterior decision and Value of Information analyses [21]. The Value of Information facilitates a quantification and optimization of risks and expected benefits before the acquirement of SHM information, i.e. before the implementation of SHM.

There is a variety of challenges associated to the quantification of the Value of SHM information, namely (1) the infrastructure system context, modelling and analysis in conjunction with SHM, (2) the translations of the approaches to real world infrastructure performance and SHM problems and (3) the interaction of several research disciplines most importantly SHM and infrastructure performance research and engineering. Current work in progress in COST TU1402 on "Quantifying the Value of Structural Health Monitoring" addresses these challenges with Working Groups ranging from the development of theoretical, classification and computational frameworks, over the development of exemplary applications, demonstrators and case studies and standardization activities to concerted dissemination and networking activities encompassing workshops, conferences and scientific missions.

In the first half of the COST Action TU1402, scientific impacts have been achieved (1) in the establishment and advancement of the scientific field for quantifying the Value of SHM Information and (2) by the provision of scientific evidence for an improved economic efficiency in the operation and maintenance and asset management of structures and infrastructure systems. The action has also partially impacted industry by making the scientific field more accessible.

\section{ACKNOWLEDGMENT}

The COST Action TU1402 on Quantifying the Value of Structural Health Monitoring is gratefully acknowledged for the inspiring discussions, contributions and workshops across the scientific and engineering disciplines with researchers, industrial experts and representatives of infrastructure operators, owners and authorities. 


\section{REFERENCES}

1. Bernal, D., '3 - Analytical Techniques for Damage Detection and Localization for Assessing and Monitoring Civil Infrastructures', in Sensor Technologies for Civil Infrastructures, ed. by M. L. Wang, J. P. Lynch and H. Sohn (Woodhead Publishing, 2014), pp. 67-92.

2. Brownjohn, J. M. W., 'Structural Health Monitoring of Civil Infrastructure', Phil. Trans. R. Soc., 365 (2006), 589-622.

3. Cha, Y.-J., and O. Buyukozturk, 'Structural Damage Detection Using Modal Strain Energy and Hybrid Multiobjective Optimization', Computer-Aided Civil and Infrastructure Engineering, 30 (2015), 347-58.

4. Döhler, M., L. Marin, D. Bernal, and L. Mevel, 'Statistical Decision Making for Damage Localization with Stochastic Load Vectors', Mechanical Systems and Signal Processing, 39 (2013), 426-40.

5. Faber, M. H., J. Qin, S. Miraglia, and S. Thöns, 'On the Probabilistic Characterization of Robustness and Resilience', Procedia Engineering (In press).

6. Faber, M. H., and S. Thöns, 'On the Value of Structural Health Monitoring', in ESREL 2013 (Amsterdam, The Netherlands: 2013).

7. Farrar, C. R., and N. A. J. Lieven, 'Damage Prognosis: The Future of Structural Health Monitoring', Philosophical Transactions of the Royal Society A-mathematical Physical and Engineering Sciences, 365 (2007), 623-32.

8. Farrar, C. R., and K. Worden, 'An Introduction to Structural Health Monitoring', Philosophical Transactions of the Royal Society A: Mathematical, Physical and Engineering Sciences, 365 (2007), 303-15.

9. Farrar, C. R., and K. Worden, Structural Health Monitoring: A Machine Learning Perspective (John Wiley \& Sons, Inc., 2013).

10. Flynn, E. B., and M. D. Todd, 'A Bayesian Approach to Optimal Sensor Placement for Structural Health Monitoring with Application to Active Sensing', Mechanical Systems and Signal Processing, 24 (2010), 891-903.

11. Haynes, C., and M. D. Todd, 'Bayesian Experimental Design for Damage Detection in a Bolted Frame', in 6th European Workshop on Structural Health Monitoring and 1st European Conference of the Prognostics and Health Management (PHM) Society (2012).

12. Huang, Q., P. Gardoni, and S. Hurlebaus, 'A Probabilistic Damage Detection Approach Using Vibration-Based Nondestructive Testing', Structural Safety, 38 (2012), 11-21.

13. JCSS, Probabilistic Model Code (JCSS Joint Committee on Structural Safety, 2006).

14. Konakli, K., and M. H. Faber, 'Value of Information Analysis in Structural Safety', Vulnerability, Uncertainty, and Risk: Quantification, Mitigation, and Management (2014), 1605-14.

15. Mandić Ivanković, A., J. Matos, S. Thöns, and N. P. Høj, eds., Proceedings of the Joint Cost Tu1402 - Tu1406 - Iabse Wc1 Workshop, The Value of Structural Health Monitoring for the Reliable Bridge Managment (Zagreb, Croatia: 2017).

16. Messervey, T., and D. Frangopol, 'Life-Cycle Cost and Performance Prediction', in Frontier Technologies for Infrastructures Engineering (CRC Press, 2009).

17. Miraglia, S., H. Brüske, and S. Thöns, eds., Proceedings of the 3rd and 4th Workshop of the Cost Action Tu1402 on Quantifying the Value of Structural Health Monitoring (Technical University of Denmark, Denmark: 2016).

18. - eds., Proceedings of the 5th Workshop of the Cost Action Tu1402 on Quantifying the Value of Structural Health Monitoring (Technical University of Denmark, Denmark: 2017).

19. Pozzi, M., and A. Der Kiureghian, 'Assessing the Value of Information for Long-Term Structural Health Monitoring', in Health monitoring of structural and biological systems 2011 (San Diego, California, United States: 2011).

20. Qin, J., S. Thöns, and M. H. Faber, 'On the Value of Shm in the Context of Service Life Integrity Management', in 12th International Conference on Applications of Statistics and Probability in Civil Engineering (ICASP12) (Vancouver, Canada: 2015).

21. Raiffa, H., and R. Schlaifer, Applied Statistical Decision Theory. Wiley classics library, Originally published: Boston : Division of Research, Graduate School of Business Administration, Harvard University, 1961. edn (New York: Wiley (2000), 1961), pp. xxviii, 356 p. 
22. Simoen, E., G. De Roeck, and G. Lombaert, 'Dealing with Uncertainty in Model Updating for Damage Assessment: A Review', Mechanical Systems and Signal Processing, 56-57 (2015), 12349.

23. Sohn, H., C. R. Farrar, F. M. Hemez, D. D. Shunk, D. W. Stinemates, B. R. Nadler, and J. J. Czarnecki, 'A Review of Structural Health Monitoring Literature: 1996-2001', (2004).

24. Straub, D., 'Value of Information Analysis with Structural Reliability Methods', Structural Safety, 49 (2014), 75-85.

25. Straub, D., E. Chatzi, E. Bismut, W. M. G. Courage, M. Döhler, M. H. Faber, J. Köhler, G. Lombaert, P. Omenzetter, M. Pozzi, S. Thöns, D. Val, and D. Zonta, 'Value of Information: A Roadmap to Quantifying the Benefit of Structural Health Monitoring', in ICOSSAR 2017 (Vienna, Austria: Accepted).

26. Sun, H., and R. Betti, 'A Hybrid Optimization Algorithm with Bayesian Inference for Probabilistic Model Updating', Computer-Aided Civil and Infrastructure Engineering, 30 (2015), 602-19.

27. Thöns, S., 'The Influence of Redundant Structural System Characteristics on the Value of Shm Information', in Proceedings of the International Workshop on Structural Health Monitoring (IWSHM) (Stanford University, Stanford, CA USA: 2015).

28. Thöns, S., 'Monitoring Based Condition Assessment of Offshore Wind Turbine Structures' (PhD thesis, ETH Zurich, 2011).

29. - ed., Quantifying the Value of Structural Health Monitoring: Proceedings of the 1st Workshop of the Cost Action Tu1402 on Quantifying the Value of Structural Health Monitoring (Technical University of Denmark, Denmark: 2015).

30. Thöns, S., and M. H. Faber, 'Assessing the Value of Structural Health Monitoring', in 11th International Conference on Structural Safety \& Reliability (ICOSSAR 2013) (New York, USA: 2013).

31. Thöns, S., M. H. Faber, and D. Val, 'On the Value of Structural Health Monitoring Information for the Operation of Wind Parks', in ICOSSAR 2017 (Vienna, Austria: Accepted).

32. Wang, M. L., J. P. Lynch, and H. Sohn, eds., Sensor Technologies for Civil Infrastructures: Applications in Structural Health Monitoring Vol. Volume 2: Applications in Structural Health Monitoring (Woodhead Publishing, 2014).

33. _ - eds., Sensor Technologies for Civil Infrastructures: Sensing Hardware and Data Collection Methods for Performance Assessment. Vol. Volume 1: Sensing Hardware and Data Collection Methods for Performance Assessment (Woodhead Publishing, 2014).

34. Worden, K., C. R. Farrar, G. Manson, and G. Park, 'The Fundamental Axioms of Structural Health Monitoring', Proc. R. Soc.: Mathematical, Physical and Engineering Sciences, 463 (2007), 163964.

35. Zonta, D., B. Glisic, and S. Adriaenssens, 'Value of Information: Impact of Monitoring on Decision-Making', Structural Control and Health Monitoring, 21 (2014), 1043-56. 